\title{
Genetic and environmental determinants of children's food preferences
}

\author{
Jane Wardle* and Lucy Cooke \\ Department of Epidemiology and Public Health, Health Behaviour Research Centre, University College London, Torrington Place, \\ London WCIE 6BT, UK
}

Omnivores have the advantage of a variety of food options but face a challenge in identifying foods that are safe to eat. Not surprisingly, therefore, children show a relative aversion to new foods (neophobia) and a relative preference for familiar, bland, sweet foods. While this may in the past have promoted survival, in the modern food environment it could have an adverse effect on dietary quality. This review examines the evidence for genetic and environmental factors underlying individual differences in children's food preferences and neophobia. Twin studies indicate that neophobia is a strongly heritable characteristic, while specific food preferences show some genetic influence and are also influenced by the family environment. The advantage of the malleability of human food preferences is that dislike of a food can be reduced or even reversed by a combination of modelling and taste exposure. The need for effective guidance for parents who may be seeking to improve the range or nutritional value of foods accepted by their children is highlighted.

Heritability: Children: Environment: Food choice: Food preferences: Neophobia

Food likes and dislikes play an important role in food choices, especially in children. Preferences are shaped by a combination of genetic and environmental factors, a better understanding of which is critical to the development of effective dietary interventions.

\section{The importance of food preferences for survival}

As omnivores, humans have adaptable dentition and digestive systems that permit them to consume a wide variety of foods. While this bestows considerable advantage, and enables survival in very different environments, there are also risks inherent in distinguishing edible from potentially poisonous items. Children must rapidly learn what is nutritious and safe to eat, and in what combination and context, if they are to avoid the potentially fatal consequences of ingesting toxins or the less immediate but equally important effects of a nutritionally inadequate diet. A combination of innate preferences and the ability to learn new preferences appears to be fundamental to this task.

\section{Characteristics of foods that influence preferences}

There are substantial differences between foods in the extent to which children like them, which to some degree, transcend cultural variations. High fat foods such as pizza and French fries, and sweet foods like chocolate or cake, feature reliably in the top 10 favourite food lists of children in the UK, France, Spain, Germany and the USA ${ }^{(1-6)}$. Vegetables, on the other hand, are almost universally towards the disliked end of the continuum $^{(2-5,7)}$.

This pattern of preferences suggests the existence of innate predispositions towards tastes. A preference for sweet tastes, measured by observation of facial expression, is universally present in neonates ${ }^{(8-10)}$, as is an aversion to sour or bitter tastes $^{(11,12)}$. These biases probably have adaptive value because sweetness indicates the presence of sugars and valuable calories, whereas bitterness or sourness may signal the presence of harmful toxins or bacteria. Anecdotally, many children also dislike foods with 'bits' or pips, the unexpected presence of which might signal contamination of some kind (de Moura, unpublished results, in press) - a characteristic that is used in marketing foods to children (e.g. 'Yo tubes with no bits'). Hot taste sensations (e.g. chilli) are often rejected initially ${ }^{(13)}$.

Whilst not present at birth, preference for salty tastes appears at around four months of age. This may be the result of experience with salt in foods, although exclusively breast-fed infants also show a preference for salty over unsalted cereal ${ }^{(14)}$, despite human breast milk being relatively low in salt content. The taste sensation known as 'umami' is imparted by a number of amino acids and ribonucleotides, e.g. monosodium glutamate (MSG). In adults and children, MSG solutions are unpalatable but the addition of MSG to foods increases their palatability ${ }^{(15-17)}$. Like salt, it appears that umami must be experienced in the context of other flavours to be preferred; i.e. it is a flavour enhancer rather than a pleasant flavour in itself.

\section{Learned features of foods that promote consumption and preference}

The other characteristic of food that is reliably associated with children's preferences is energy density ${ }^{(18,19)}$. Even amongst fruit and vegetables - which are all relatively low in energy - children appear to prefer those delivering most calories per gram such as bananas and potatoes, rather than courgettes and melon ${ }^{(20)}$. Given that energy density is not a taste per se, it is 
likely to be learned through experience of the post-ingestive consequences of eating particular foods. Energy-dense foods are relatively satiating and therefore pleasant feelings of fullness result from consuming them, which could lead to a learned preference for their taste, texture or smell. This has been demonstrated experimentally by adding energy in the form of starch to soups. Following experience with eating the soups that allowed taste and post-ingestive consequences to be associated, adults showed increased liking for the higher-energy soups, particularly when they were hungry ${ }^{(21)}$. Studies by Leann Birch and colleagues demonstrated that after a number of exposures children prefer flavours associated with higher-energy drinks ${ }^{(22)}$ and higher-fat yogurts ${ }^{(23)}$ compared to flavours associated with lower-energy and low-fat versions. A predisposition to 'flavour-consequence learning' may have served an adaptive function in the impoverished food environment of the distant past, but probably raises the risk of overweight and obesity in the plentiful food environment of the twenty-first century.

The post-ingestive consequences of eating are not always pleasant and children can also learn aversions to a particular food if they experience negative consequences such as nausea and vomiting after consuming it. Once an aversion is established, it is not easily extinguished and avoidance of the food may persist for many years. Learned aversions are formed most readily to unfamiliar foods and this is perhaps why they occur frequently in childhood where diets tend to be more limited than in adulthood and when many foods are still novel ${ }^{(24)}$.

Although not strictly a property of food itself, the extent to which a food is familiar impacts strongly upon its acceptability. In an early study, familiarity accounted for over half of the variance in preschoolers' preferences for a selection of sandwiches, with a further $23 \%$ accounted for by sweetness ${ }^{(25)}$. For many children - and some adults - unfamiliarity is a reason to shun a novel food. In terms of the adaptive origins of a preference for familiarity, it is plausible that familiar tastes provide an indication of the likely safety of the food being presented. Giving a novel food a familiar flavour (e.g. adding tomato ketchup or curry) can also increase a child's willingness to try $i^{(26)}$. Familiarity appears to be a matter of taste rather than mere sight, and there are a wealth of studies (discussed in the later section on exposure) demonstrating that repeated exposure to the taste of a food can increase liking for it.

Social facilitation is another striking phenomenon in food preferences. In many animal species, seeing others eating the food, or even smelling the food on their mouth after consumption has taken place out of sight, increases acceptance ${ }^{(27,28)}$. If conspecifics eat a food without negative consequences, this is presumably an indication that consumption is safe and it allows healthy dietary choices to be facilitated and harmful dietary choices to be avoided. The same phenomenon is seen in children, who are significantly more willing to try something unfamiliar if they have observed someone else eating it ${ }^{(29)}$. Parents utilise this feature spontaneously when they take a mouthful of the child's food and then mime exaggerated signs of enjoyment.

The other form of learning derives from culture-specific beliefs about appropriate and inappropriate contexts to eat certain foods. One such context is time of day. For example, it is common in Scandinavian countries to eat fish at breakfast and in Germany to eat cheese and cured meat. In India, lentils may be served and in Japan, rice and miso soup. Although a North American child might enjoy such foods at other times of the day, their presentation at breakfast may be met with rejection or even disgust. Children as young as three or four years of age appear to internalise their own culture's ideas about the appropriateness of certain foods at certain mealtimes ${ }^{(30)}$.

Culture also dictates to a large extent the actual foods that a child is exposed to and therefore prefers. Foodstuffs that would be deemed unsuitable for young children in Westernised countries may be routinely offered to infants of other cultures. Even innately dislikeable substances such as chilli pepper, are generally accepted and liked by children growing up in cultures where they are widely used ${ }^{(13)}$. Clearly, it is adaptive for children to grow to prefer the foods that are locally available.

\section{Variability in food preferences between individuals}

As well as variation between foods there is variability between children in their food preferences. Even among foods that are generally accepted, some individuals express specific dislikes. In a study of 4-5 year-olds' food preferences, we found that the average number of foods that were disliked out of a list of 94 common foods was 10 . However, food dislikes were not random: staples (e.g. bread) and sweet foods (e.g. chocolate) were rarely disliked (though some individuals did not like them as much as others) while vegetables and protein foods attracted the largest number of dislikes. Interestingly, across foods, the number of children disliking a food was strongly negatively correlated with the number that had tried it, suggesting either that parents avoid offering widely disliked foods to children or that the aversive qualities of some foods (e.g. smell, appearance) make many children reluctant even to try them ${ }^{(31)}$.

Children also vary in their total number of dislikes. Several dimensions have been identified as related to a higher number of food dislikes, including 'fussiness', 'pickiness' and 'neophobia', and there is an active debate about whether these are distinct dimensions. Food neophobia - or dislike of novel foods - has attracted a good deal of attention. While most children exhibit some degree of caution in response to unfamiliar foods, roughly $20-30 \%$ are significantly neophobic. In a rare longitudinal study, Skinner and colleagues found that food neophobia early in life was related to the number of foods disliked or never tried at age 8 years and negatively related to the number of foods liked ${ }^{(4)}$.

Recent research suggests that the association of neophobia scores with liking is not the same for all types of foods, and that certain types of food are more likely to be rejected by neophobic children than others. In a survey of over five hundred and fifty parents of preschoolers, children who were rated (by their parents) as more neophobic ate fruit, vegetables and protein foods, but not other foods, less frequently than their less neophobic peers ${ }^{(32)}$. This finding was replicated in a sample of 5-6 year olds, using observed food intakes ${ }^{(33)}$ : higher neophobia was associated with lower consumption of fruit (grapes), vegetables (carrots or tomatoes) and protein foods (chicken and cheese) during school lunches, but there was no association with consumption of starchy, fatty or sugary foods. 
What was apparent in this last study was that neophobic children were not only rejecting novel foods but were also more likely to reject certain classes of familiar foods, which is more characteristic of 'pickiness'. Despite the assertion by some that the two are distinct constructs ${ }^{(34)}$, neophobia and pickiness appear to be closely linked, and the tendency to reject novel foods goes hand-in-hand with a tendency to reject less palatable but familiar foods. In developing the Children's Eating Behaviour Questionnaire, Wardle and colleagues found that 'food fussiness' emerged as a factor, with the items loading on this factor including 'picky' items such as 'My child enjoys a wide variety of foods' (reverse scored) as well as traditional 'neophobia' items such as 'My child enjoys tasting new foods' (reverse scored), supporting this idea ${ }^{(31)}$.

Studies of pickiness have found associations with dietary quality, although results have varied. A number of studies have found that picky children have a less varied diet and are especially unlikely to eat vegetables ${ }^{(35-37)}$ although others have found no differences between picky and non-picky infants and toddlers in terms of consumption of foods from the major food groups ${ }^{(38)}$. However, given the difficulty of assessing young children's diets, these results suggest that pickiness or related traits are likely to influence children's food choices and that this may impact on the quality of their diet.

\section{Genetic influences on food preferences}

There are good reasons to suspect some genetic influence on food acceptance, not least because genetic factors are implicated in a number of factors - such as taste sensitivity that are likely to be related to food choice. In addition, some food dislikes show themselves early in life, before there is any evidence for aversive experiences.

One approach has been to examine family similarity in food preferences. Within-family (usually parent-child) correlations are typically modest ${ }^{(39-42)}$, although sibling-sibling similarities tend to be stronger than parent-child similarities ${ }^{(41)}$, perhaps because they are similar ages. However, without large family pedigrees, it is difficult to distinguish genetic and environmental influences in family studies.

A stronger test of genetic influence on food preferences is provided by twin studies. The twin design takes advantage of the fact that monozygotic (MZ) twins are genetically identical, whereas dizygotic (DZ) twins share on average only $50 \%$ of their segregating genes (the same as siblings). Heritability can therefore be estimated from the extent to which MZ pairs are on average more similar than DZ twins, although when heritability is low, large sample sizes are needed to achieve accurate estimates. Few studies in the food preference area have been carried out with large enough samples to detect moderate heritabilities ${ }^{(43,44)}$, and most have used only very small numbers of foods. A recent exception used a large sample of twins and an extensive list of foods which were grouped empirically into four categories: dessert foods, vegetables, fruits and protein foods on the basis of a factor structure of food preferences previously documented ${ }^{(31)}$. In this study high heritability was found for protein foods $(0.78)$, with moderate heritability for fruits $(0.51)$, vegetables $(0.37)$ and dessert foods $(0 \cdot 20)^{(45)}$.
Genetic variation in taste perception might contribute to differences in food preferences, particularly for fruits and vegetables. Thioureas and related compounds are present in many vegetables and other edible plants and have a bitter taste. Variation in sensitivity to the taste of thioureas is known to be genetically based. Around $70 \%$ of white individuals in the USA and Western Europe perceive these compounds to be moderately to intensely bitter; and of these 'tasters', a small proportion are highly sensitive, and classified as 'supertasters'. The remaining $30 \%$ of the population perceive thioureas as only very slightly bitter or completely tasteless ${ }^{(46)}$. The most frequently studied of these compounds are phenylthiocarbamide (PTC) and 6- $n$-propylthiouracil (PROP).

In adults, higher sensitivity to PROP has been associated with lower acceptance of cruciferous and other green vegetables $^{(47-49)}$, salad, fruit ${ }^{(50)}$ and a variety of other bitter foods including coffee, cheddar cheese, tofu and green tea ${ }^{(51,52)}$. Findings are not unequivocal, however ${ }^{(48-50,53,54)}$. In children, PROP sensitivity has sometimes been associated with lower acceptance of such bitter-tasting vegetables as raw spinach and broccoli in laboratory taste tests ${ }^{(55-57)}$, but not with everyday intake of vegetables as reported by parents ${ }^{(56,58)}$. Interestingly, PROP non-tasters have shown increased liking with increasing sucrose concentration while tasters show decreased liking ${ }^{(59)}$, which might suggest differences in their liking for fruit which is naturally sweet. However, the few studies that have investigated the relationship between PROP status and fruit acceptance in children have found no differences between tasters and non-tasters ${ }^{(56,58)}$ and not all researchers have replicated the finding of increased liking for sweet taste in non-tasters ${ }^{(60)}$.

Despite the attractiveness of the idea that variation in taste sensitivities could underlie food dislikes, the weight of the evidence is that PROP taster status has only limited influence on food preferences in everyday life. One alternative genetic explanation could be that neophobia/pickiness are under a degree of genetic control and pickier children are more reluctant to tolerate less palatable foods. Parents - responding to their picky child's limited diet, and worried about their overall energy intake - may 'give in' and serve the child foods it prefers, therefore further reinforcing their avoidance of any but the most palatable foods.

\section{Heritability of pickiness/neophobia}

Neophobia has been associated with personality traits such as emotionality $^{(61)}$ and anxiety ${ }^{(62)}$, which have strong genetic links, suggesting that neophobia itself might also be heritable. Moderate parent/child or sibling/sibling correlations have been observed $^{(32,61,63-66)}$, but these could be either genetic or environmental. A recent study used the Child Food Neophobia Scale $(\text { CFNS })^{(66)}$ in a large sample $(n=5390)$ of $9-11$ yearold MZ and DZ twin pairs to examine the relative contribution of genes and environment. The results showed a strong genetic influence on neophobia, with model-fitting estimating heritability at $78 \%{ }^{(67)}$. These results are further supported by results from a study of Finnish families and British female twin pairs, in which heritability for neophobia was estimated at $69 \%$ and $67 \%$ respectively ${ }^{(68)}$. This is consistent with the idea that the trait of reluctance to accept novel or less palatable foods could play a role in dislikes for specific foods. 


\section{Environmental influence on variation in preferences}

Twin studies have the advantage of not only being able to estimate genetic influence, but also to estimate the influence of a shared family environment. In simple terms, this calculation is based on assessing the extent to which the twins' similarity for a trait is greater than would be expected from the heritability of that trait. In the twin study described above, the evidence was that there was no shared environment effect for neophobia; twins were as similar in neophobia scores as predicted from their genetic resemblance but no more ${ }^{(67)}$.

However, different results have been found for preferences for specific categories of food. Similarity in liking for fruits, vegetables and dessert foods within twin pairs was found to be a joint function of shared genes and shared environment ${ }^{(45)}$. This is consistent with the idea that although parental feeding styles may not be able to influence general tendencies towards disliking novel and unpalatable foods, they do have more influence when it comes to helping the child to accept specific individual foods.

\section{Modifying food preferences}

Although humans are predisposed to prefer certain tastes and regard novel foods with suspicion, they are also predisposed to learn through experience, and therefore environmental factors are very influential in food preferences. These factors may range from the availability of foods in local shops to the extent of TV advertising that a child is exposed to, but in the lives of young children, the most important factors are those related to parents and the home.

\section{Exposure}

Given the influence of familiarity on children's food, providing children with frequent opportunities to taste a wide variety of novel foods is likely pay dividends in terms of healthier eating habits. A growing body of research has demonstrated that from the very earliest age (and even before birth), experience with a tastes increases its acceptance. Julie Mennella and her colleagues have completed a number of studies demonstrating that exposure to flavours in amniotic fluid and in breast milk increases acceptance of the same flavours at weaning ${ }^{(69)}$. Early introduction of foods during weaning is associated with greater acceptance in later childhood ${ }^{(32,70,71)}$ and experimental studies have repeatedly shown that regular and repeated opportunities to sample tiny tastes of unfamiliar foods increases both liking and consumption of those exposed foods ${ }^{(62,72-77)}$. Although there are circumstances in which exposure works less well (e.g. when foods are unusual or widely disliked, or when exposure is too frequent), recent research has shown that it is a simple and effective technique that parents can employ to increase children's vegetable preferences $^{(78)}$. For a review of this literature see Cooke, $2007^{(79)}$.

\section{Modelling}

Parents' consumption of fruit and vegetables was the strongest predictor of their child's intake in a recent survey of over 550 families with preschool children ${ }^{(33)}$. A number of factors are likely to contribute to this, including the foods that are available in the home, but it is likely to be due in part to children's tendency to imitate the behaviour of significant others. Modelling's effect on consumption has been repeatedly documented in the experimental literature on children's food choices ${ }^{(80-83)}$. Observing others eating may change preferences directly, or alternatively it may increase the likelihood of consumption, which then promotes liking through taste exposure.

\section{Reward}

The promise of a reward is a common strategy used by caregivers to encourage consumption in an unwilling child. In certain circumstances, it appears that treating a food in this way - as the instrumental component of a contingency - can actually reduce liking ${ }^{(73,84,85)}$. On the other hand, using food as a reward increases children's liking ${ }^{(86)}$. For example Newman and Taylor found that liking for a snack was reduced after consumption was rewarded by being offered a better-liked snack in 4-7 year olds ${ }^{(85)}$. Likewise, Birch et al found that preference for a drink that was rewarded declined whilst preference for other juices that were consumed without reward increased $^{(87)}$. A further study by this group found that rewards produced negative shifts in preference for drinks whether they were verbal or tangible ${ }^{(84)}$. Our own research has demonstrated that children who received a 'sticker' as a reward for eating pieces of red pepper increased their liking and consumption of pepper over 10 rewarded days of tasting, but there was a trend for the effect to be less strong than in the group who tasted the pepper each day without being rewarded. Reward may therefore weaken the positive effect of exposure alone ${ }^{(77)}$.

Explanations for paradoxical effects of reward generally draw on the child's interpretation of the context in which the foods are presented. Social psychologists argue that being given an extrinsic and tangible reward for performing a behaviour undermines an individual's intrinsic motivation, resulting in a reduction in the performance of the behaviour in future ${ }^{(88)}$. Others point out that humans do very little without some form of extrinsic reward and that what matters is the type and timing of the reward ${ }^{(89)}$. Certainly, there are children who cannot be persuaded to try a food without some incentive, and if the promise of a gold star or sticker provides the required incentive to start the exposure process, it may be a necessary step on the road to improving a child's eating patterns.

\section{Conclusions}

Children's food preferences are important determinants of their food intake and as such are of interest to researchers and practitioners alike. The predisposition to prefer sweet and salty tastes and to learn to prefer energy-dense foods may once have been adaptive, but are more likely to promote over-consumption and obesity in the plentiful $21^{\text {st }}$ century food environment. The innate tendency to reject sour and bitter foods may have protected from toxins in the past but now contributes to the widespread dislike of vegetables among children and many adults; to the detriment of their dietary quality. On top of the predispositions towards acceptance and rejection shown by the whole species, there are also differences between people, both in specific food preferences and general tendencies towards neophobia/pickiness. We hypothesise that neophobia/ 
pickiness are related traits that include the tendency to be put off eating a food either by lower palatability or greater novelty; hence the association between neophobia and specific food preferences. There is now evidence that neophobia is a strongly heritable characteristic while specific food preferences are modestly heritable and are also influenced by the family environment. Thus food preferences are the product of an interplay between genetic and environmental factors resulting in substantial individual differences in the extent to which children are suspicious and fussy about food in general and in their likes and dislikes for specific foods. The advantage of the malleability of human food preferences is that dislike for a food can be reduced or even reversed by a combination of modelling and taste exposure. Unfortunately, few parents receive any guidance in how to promote food acceptance and a challenge for future research is to develop effective interventions that can be widely disseminated, to improve the eating patterns of young children.

\section{Conflict of interest statement}

Research described in this manuscript was supported by Cancer Research UK, the Biotechnology and Biological Sciences Research Council (UK) and the Economic and Social Sciences Research Council (UK). None of the authors has any conflicts of interest to report.

\section{References}

1. Bellisle F, Rolland-Cachera MF \& Kellogg Scientific Advisory Committee 'Child and Nutrition' (2000) Three consecutive $(1993,1995,1997)$ surveys of food intake, nutritional attitudes and knowledge, and lifestyle in 1000 French children, aged 9-11 years. J Hum Nutr Diet 13, 101-111.

2. Cooke L \& Wardle J (2005) Age and gender differences in children's food preferences. Br J Nutr 93, 741-746.

3. Diehl JM (1999) Food preferences of 10- to 14-year-old boys and girls. Schweiz Med Wochenschr 129, 151-161.

4. Skinner JD, Caruth BR, Bounds W \& Zeigler PJ (2002b) Children's food preferences: a longitudinal analysis. $J$ Am Diet Assoc 102, 1638-1647.

5. Ton Nu C, MacLeod P \& Barthelemy J (1996) Effects of age and gender on adolescents' food habits and preferences. Food Qual Preferences 7, 251-262.

6. Wardle J, Guthrie CA, Sanderson S, Birch LL \& Plomin R (2001a) Food and activity preferences in children of lean and obese parents. Int J Obes $\mathbf{2 5}, 977$.

7. Perez-Rodrigo C, Ribas L, Serra-Majem L \& Aranceta J (2003) Food preferences of Spanish children and young people: the enKid study. Eur J Clin Nutr 57, Suppl. 1, S45-S48.

8. Beauchamp GK \& Moran M (1982) Dietary experience and sweet taste preference in human infants. Appetite 3, 139-152.

9. Desor JA, Maller O \& Turner RE (1973) Taste in acceptance of sugars by human infants. J Comp Physiol Psychol 3, 496-501.

10. Desor JA, Maller O \& Turner RE (1977) Preference for sweet in humans: infants, children, and adults. In Taste and Development: the Genesis of Sweet Preference, pp. 161-172 [JM Weiffenbach, editor]. US Government Printing Office: Washington, DC.

11. Desor JA, Maller O \& Andrews K (1975) Ingestive responses of human newborns to salty, sour, and bitter stimuli. J Comp Physiol Psychol 89, 966-970.
12. Steiner JE (1979) Facial expressions of the neonate infant indicating the hedonics of food related stimuli. In Taste and Development: the Genesis of Sweet Preference, pp. 173-189 [JM Weiffenbach, editor]. US Department of Health and Human Sciences: Washington, DC.

13. Rozin P \& Schiller D (1980) The nature and acquisition of a preference for chili pepper by humans. Motiv Emotion 4, $77-101$.

14. Harris G, Thomas A \& Booth DA (1990) Development of salt taste preference in infancy. Dev Psychol 26, 534-538.

15. Beauchamp GK, Bachmanov A \& Stein LJ (1998) Development and genetics of glutamate taste preference. Ann N Y Acad Sci 855, 412-416.

16. Beauchamp GK \& Pearson P (1991) Human development and umami taste. Physiol Behav 49, 1009-1012.

17. Vazquez M, Pearson PB \& Beauchamp GK (1982) Flavor preferences in malnourished Mexican infants. Physiol Behav 28, 513-519.

18. Birch LL, McPhee L, Steinberg L \& Sullivan S (1990a) Conditioned flavor preferences in young children. Physiol Behav 47, 501-505.

19. Birch LL (1992) Children's preferences for high-fat foods. Nutr Rev 50, 249-255.

20. Gibson EL \& Wardle J (2003) Energy density predicts preferences for fruit and vegetables in 4 year-old children. Appetite 41, 97-98.

21. Booth DA, Mather P \& Fuller J (1982) Starch content of ordinary foods associatively conditions human appetite and satiation, indexed by intake and eating pleasantness of starch-paired flavours. Appetite 3, 163-184.

22. Birch LL, McPhee L, Steinberg L \& Sullivan S (1990b) Conditioned flavor preferences in young children. Physiol Behav 47, 501-505.

23. Johnson SL, McPhee L \& Birch LL (1991) Conditioned preferences: young children prefer flavors associated with high dietary fat. Physiol Behav 50, 1245-1251.

24. McFarlane T \& Pliner P (1997) Increasing willingness to taste novel foods: effects of nutrition and taste information. Appetite 28, 227-238.

25. Birch LL (1979) Dimensions of preschool children's food preferences. J Nutr Educ 11, 77-80.

26. Pliner P \& Stallberg-White C (2000) "Pass the ketchup, please": familiar flavors increase children's willingness to taste novel foods. Appetite 34, 95-103.

27. Galef BG Jr (1996) Food selection: problems in understanding how we choose foods to eat. Neurosci Biobehav Rev 20, 67-73.

28. Visalberghi E \& Addessi E (2000) Seeing group members eating a familiar food enhances the acceptance of novel foods in capuchin monkeys. Anim Behav 60, 69-76.

29. Addessi E, Galloway AT, Visalberghi E \& Birch LL (2005) Specific social influences on the acceptance of novel foods in 2-5-year-old children. Appetite 45, 264-271.

30. Birch LL, Billman J \& Richards SS (1984) Time of day influences food acceptability. Appetite 5, 109-116.

31. Wardle J, Sanderson S, Gibson EL \& Rapoport L (2001b) Factor-analytic structure of food preferences in four-year-old children in the UK. Appetite 37, 217-223.

32. Cooke L, Wardle J, Gibson EL, Sapochnik M, Sheiham A \& Lawson M (2004) Demographic, familial and trait predictors of fruit and vegetable consumption by preschool children. Public Health Nutr 7, 295-302.

33. Cooke L, Carnell S \& Wardle J (2006) Food neophobia and mealtime food consumption in 4-5 year old children. Int $J$ Behav Nutr Phys Act 6, 3-14.

34. Galloway AT, Lee Y \& Birch LL (2003) Predictors and consequences of food neophobia and pickiness in young girls. $J \mathrm{Am}$ Diet Assoc 103, 692-698. 
35. Jacobi C, Agras WS, Bryson S, et al. (2003) Behavioural validation, precursors and concomitants of picky eating in childhood. J Am Acad Child Adolesc Psychiatry 42, 76-84.

36. Galloway AT, Fiorito L, Lee Y \& Birch LL (2005) Parental pressure, dietary patterns, and weight status among girls who are "picky eaters". J Am Diet Assoc 105, 541-548.

37. Carruth BR, Skinner J, Houck J, Moran J 3rd, Coletta F \& Ott D (1998) The phenomenon of "picky eater": a behavioral marker in eating patterns of toddlers. $J$ Am Coll Nutr 17, $180-186$

38. Carruth BR, Ziegler PJ, Gordon A \& Barr SI (2004) Prevalence of picky eaters among infants and toddlers and their caregivers' decisions about offering a new food. $J$ Am Diet Assoc 104, Suppl. 1, S57-S64.

39. Birch LL (1980b) The relationship between children's food preferences and those of their parents. J Nutr Educ 12, 14-18.

40. Logue AW, Logue CM, Uzzo RG, McCarty MJ \& Smith ME (1988) Food preferences in families. Appetite 10, 169-180.

41. Pliner P \& Pelchat M (1986) Similarities in food preferences between children and their siblings and parents. Appetite 7, 333-342.

42. Rozin P \& Millman L (1987) Family environment, not heredity, accounts for family resemblances in food preferences and attitudes: a twin study. Appetite 8, 125-134.

43. Falciglia GA \& Norton PA (1994) Evidence for a genetic influence on preference for some foods. J Am Diet Assoc 94, 154-158.

44. Krondl M, Coleman P, Wade J \& Milner J (1983) A twin study examining the genetic influence on food selection. Hum Nutr Appl Nutr 37A, 189-198.

45. Breen FM, Plomin R \& Wardle J (2006) Heritability of food preferences in young children. Physiol Behav 88, 443-447.

46. Bartoshuk LM \& Beauchamp GK (1994) Chemical senses. Annu Rev Psychol 45, 419-449.

47. Dinehart ME, Hayes JE, Bartoshuk LM, Lanier SL \& Duffy VB (2006) Bitter taste markers explain variability in vegetable sweetness, bitterness, and intake. Physiol Behav 87, 304-313.

48. Drewnowski A, Henderson SA, Shore AB \& Barratt-Fornell A (1998) Sensory responses to 6- $n$-propylthiouracil (PROP) or sucrose solutions and food preferences in young women. Ann N Y Acad Sci 855, 797-801.

49. Drewnowski A, Henderson SA, Hann CS, Berg WA \& Ruffin MT (2000) Genetic taste markers and preferences for vegetables and fruit of female breast care patients. J Am Diet Assoc 100, 191-197.

50. Yackinous CA \& Guinard JX (2002) Relation between PROP (6- $n$-propylthiouracil) taster status, taste anatomy and dietary intake measures for young men and women. Appetite 38, 201-209.

51. Drewnowski A, Henderson SA, Levine A \& Hann C (1999) Taste and food preferences as predictors of dietary practices in young women. Public Health Nutr 2, 513-519.

52. Gayathri DA, Henderson SA \& Drewnowski A (1997) Sensory acceptance of Japanese green tea and soy products is linked to genetic sensitivity to 6- $n$-propylthiouracil. Nutr Cancer 29, $146-151$

53. Pasquet P, Oberti B, El AJ \& Hladik CM (2002) Relationships between threshold-based PROP sensitivity and food preferences of Tunisians. Appetite 39, 167-173.

54. Duffy VB \& Bartoshuk LM (2000) Food acceptance and genetic variation in taste. $J$ Am Diet Assoc 100, 647-655.

55. Bell KI \& Tepper BJ (2006) Short-term vegetable intake by young children classified by $6-n$-propylthoiuracil bitter-taste phenotype. Am J Clin Nutr 84, 245-251.

56. Keller KL, Steinmann L, Nurse RJ \& Tepper BJ (2002) Genetic taste sensitivity to 6- $n$-propylthiouracil influences food preference and reported intake in preschool children. Appetite 38, 3-12.

57. Turnbull B \& Matisoo-Smith E (2002) Taste sensitivity to 6- $n$-propylthiouracil predicts acceptance of bitter-tasting spinach in 3-6-y-old children. Am $J$ Clin Nutr 76, $1101-1105$.

58. Keller KL \& Tepper BJ (2004) Inherited taste sensitivity to 6- $n$ propylthiouracil in diet and body weight in children. Obes Res 12, 904-912.

59. Looy H \& Weingarten HP (1992) Facial expressions and genetic sensitivity to 6- $n$-propylthiouracil predict hedonic response to sweet. Physiol Behav 52, 75-82.

60. Drewnowski A (1997) Taste preferences and food intake. Annu Rev Nutr 17, 237-253.

61. Pliner P \& Loewen ER (1997) Temperament and food neophobia in children and their mothers. Appetite 28, 239-254.

62. Pliner P, Pelchat M \& Grabski M (1993) Reduction of neophobia in humans by exposure to novel foods. Appetite 20, $111-123$

63. Falciglia GA, Pabst SM, Couch SC \& Goody C (2004) Impact of parental food choices on child food neophobia. Children's Health Care 33, 217-225.

64. Koivisto Hursti UK \& Sjoden PO (1997) Food and general neophobia and their relationship with self-reported food choice: familial resemblance in swedish families with children of ages 7-17 years. Appetite 29, 89-103.

65. Koivisto UK \& Sjoden PO (1996) Food and general neophobia in swedish families: parent-child comparisons and relationships with serving specific foods. Appetite 26, 107-118.

66. Pliner P (1994) Development of measures of food neophobia in children. Appetite 23, 147-163.

67. Cooke LJ, Haworth CA \& Wardle J (2007) Genetic and environmental influences on children's food neophobia. Am J Clin Nutr 86, 428-433.

68. Knaapila A, Tuorila H, Silventoinen K, et al. (2007) Food neophobia shows heritable variation in humans. Physiol Behav, (Epublication ahead of print version).

69. Mennella JA, Jagnow CP \& Beauchamp GK (2001) Prenatal and postnatal flavor learning by human infants. Pediatrics 107, E88.

70. Cashdan E (1994) A sensitive period for learning about food. Hum Nat 5, 279-291.

71. Skinner JD, Carruth BR, Bounds W, Ziegler PJ \& Reidy K (2002a) Do food-related experiences in the first 2 years of life predict dietary variety in school-aged children? J Nutr Educ Behav 34, 310-315.

72. Birch LL, McPhee L, Shoba BC, Pirok E \& Steinberg L (1987) What kind of exposure reduces children's children's food neophobia? Looking vs tasting. Appetite 9, 171-178.

73. Birch LL \& Marlin DW (1982) I don't like it; I never tried it: effects of exposure on two-year-old children's food preferences. Appetite 3, 353-360.

74. Pliner P (1982) The effects of mere exposure on liking for edible substances. Appetite 3, 283-290.

75. Sullivan SA \& Birch LL (1990) Pass the sugar, pass the salt: experience dictates preference. Dev Psychol 26, 546-551.

76. Sullivan SA \& Birch LL (1994) Infant dietary experience and acceptance of solid foods. Paediatrics 93, 271-277.

77. Wardle J, Herrera ML, Cooke L \& Gibson EL (2003b) Modifying children's food preferences: the effects of exposure and reward on acceptance of an unfamiliar vegetable. Eur J Clin Nutr 57, 341-348.

78. Wardle J, Cooke L, Gibson EL, Sapochnik M, Sheiham A \& Lawson M (2003a) Increasing children's acceptance of vegetables: a randomised trial of guidance to parents. Appetite $\mathbf{4 0}$, $155-162$. 
79. Cooke L (2007) The importance of exposure for healthy eating in childhood: a review. J Hum Nutr Diet 20, 294-301.

80. Birch LL (1980a) Effects of peer models' food choices and eating behaviors on preschoolers' food preferences. Child Dev 51, 489-496.

81. Duncker K (1938) Experimental modification of children's food preferences through social suggestion. J Abnorm Soc Psychol 33, 489-507.

82. Harper L \& Sanders KM (1975) The effect of adults' eating on young children's acceptance of unfamiliar foods. J Exp Child Psychol 20, 206-214.

83. Hobden K \& Pliner P (1995) Effects of a model on food neophobia in humans. Appetite 25, 101-114.

84. Birch LL, Marlin DW \& Rotter J (1984) Eating as the 'means' activity in a contingency: effects on young children's food preference. Child Dev 55, 431-439.
85. Newman J \& Taylor A (1992) Effect of a means-end contingency on young children's food preferences. $J$ Exp Child Psychol 64, 200-216.

86. Birch LL, Zimmerman S \& Hind H (1980) The influence of social-affective context on the development of children's food preferences. Child Dev 52, 856-861.

87. Birch LL, Birch D, Marlin DW \& Kramer L (1982) Effects of instrumental consumption on children's food preference. Appetite 3, 125-134.

88. Deci EL, Koestner R \& Ryan RM (1999) A metaanalytic review of experiments examining the effects of extrinsic rewards on intrinsic motivation. Psychol Bull 125, $627-668$.

89. Cameron J, Banko KM \& Pierce WD (2001) Pervasive negative effects of rewards on intrinsic motivation: The myth continues. Behav Anal 24, 1-44. 